\title{
La gestión de la comunicación de riesgo a través de Facebook: Análisis exploratorio de las estrategias iniciales de 12 gobiernos de América Latina frente a la pandemia de la COVID 19
}

\author{
Risk communication management through Facebook: \\ Exploratory analysis of the initial strategies of 12 Latin American \\ governments in the COVID 19 pandemic
}

Cárdenas Ruiz, J. D. y Pineda Rodríguez, N. C. ${ }^{1}$

Recibido: 14-05-2021 - Aceptado: 15-08-2021

https://doi.org/10.26441/RC20.2-2021-A4

\begin{abstract}
RESUMEN: La pandemia del Sars-Cov 2 hizo replantear las formas de comunicación de los gobiernos. Las estrategias discursivas en cuanto al uso de medios y las formas de comunicación se volcaron a entender la pandemia y comunicar el riesgo. Este artículo analiza los casos de doce países latinoamericanos frente a la capacidad del Ejecutivo en la adaptación a la comunicación de riesgo, como principal herramienta para modificar hábitos y conductas con el fin de prevenir el riesgo, así como el uso potencial que le otorgaron a las redes sociales para establecer un contacto inmediato y a tiempo real con sus ciudadanos. Para tal fin, el estudio se sustenta teóricamente desde los estudios de la comunicación de riesgo, la Agenda Setting, el Framing y las redes sociales. La investigación tomó las cuentas oficiales de Facebook de Presidencia, Ministerios/secretarías de salud y cuentas personales presidenciales para analizar el contenido de las publicaciones, desde el primer caso de contagio reportado en cada país, hasta el 30 de junio, fecha de corte. Se realizó un muestreo aleatorio estratificado por cada país, dando como resultado un total de 1420 publicaciones analizadas. Los resultados principales van desde la multiplicación de seguidores a estas cuentas oficiales, en los 3 primeros meses de la llegada del virus a cada país, hasta los cinco temas y enfoques que cada nación logró instalar en la Agenda para comunicar a sus habitantes el fenómeno. Se puede identificar una diferencia entre el discurso que se maneja en la red social y el que se percibe en los pronunciamientos presidenciales en los medios tradicionales.
\end{abstract}

Palabras clave: América Latina; Covid-19; comunicación de riesgo; redes sociales; Agenda Setting; Framing.

ABSTRACT: The Sars-Cov 2 pandemic made governments rethink the forms of communication. Discursive strategies regarding the use of media and forms of communication focused on understanding the pandemic and communicating the risk. This article analyzes the cases of twelve Latin American countries regarding the Executive's ability to adapt to risk communication, as the main tool for modifying habits and behaviors to prevent risk, as well as the potential use they gave to the social networks to establish immediate and real-time contact with its citizens. For this purpose, the study is theoretically based on the studies of risk communication, Agenda Setting, Framing and social networks. The investigation took the official

\footnotetext{
1 Juan David Cárdenas Ruiz es Magister en estudios políticos, politólogo, especialista en opinión pública y marketing político. Además, es jefe del Departamento de comunicación pública, investigador del Observatorio de Medios de la Facultad de Comunicación Social y Periodismo de la Universidad de La Sabana (Colombia) en la línea de investigación en comunicación pública juancar@unisabana.edu.co, https://orcid.org/0000-0003-4823-1572

Nidia Katherine Pineda Rodríguez es Comunicadora social, periodista, docente catedrática y coordinadora de Diplomado en marketing de gobierno en la Facultad de Comunicación de la Universidad de La Sabana (Colombia). Maestrante en Comunicación Política de la Universidad Austral. nidia.pineda1@unisabana.edu.co. https://orcid.org/0000-0001-9190-0589
} 
Facebook accounts of the Presidency, Ministries / organizations in charge of public health and presidential personal accounts to analyze the content of the publications, from the first case of contagion reported in each country, until June 30 , date of cut. A stratified random sampling was carried out for each country, resulting in a total of 1420 publications analyzed. The main results range from the multiplication of followers of followers to these official accounts, in the first 3 months of the arrival of the virus in each country, to the five themes and approaches that each nation managed to install in the agenda to communicate to its inhabitants the phenomenon. A difference can be identified between the speech that is handled in the social network and that perceived in the presidential pronouncements in the traditional media.

Keywords: Latin America; Covid-19; risk communication; social media; agenda setting; framing.

\section{Introducción}

La pandemia de la COVID-19 supuso para América Latina un escenario de alta incertidumbre que desnudó las brechas de desigualdad entre países y al interior de cada una de las sociedades, así como también la fragilidad e incapacidad de las instituciones estatales y la agudización de patrones culturales que han dificultado aún más el poder hacer frente al problema de una manera más eficiente y segura.

La pandemia llega a América Latina hacia finales de febrero, tres meses después de los primeros casos confirmados en China y casi al tiempo con el primer pico de la enfermedad en Europa, que puso en jaque a los sistemas de salud de los países más desarrollados del continente, llevó a la imposición de duras restricciones y a muerte de miles de ciudadanos del viejo continente.

Se pensaba que, ante el conocimiento previo de las consecuencias de la pandemia, y las medidas de choque que en muchos países se tomaron como cuarentenas y restricciones de movilidad para tener márgenes de fortalecimiento de los sistemas de salud, el impacto de la pandemia sería menor, pero, por lo contrario, la situación no tardó en empezar a producir efectos adversos de salud pública y fuertes presiones sobre las economías nacionales.

Los pronunciamientos de muchos de los gobernantes, cuando el virus aún no hacía presencia en la región, oscilaban entre la subestimación, la suspicacia, la negación y hasta la superstición. Como lo afirma Inerarity (2020).

Al comienzo de la crisis muchos actores políticos y analistas la consideran algo parecido a una gripe estacional, localizada en una región de un país lejano, y nos advertían de que lo único que debíamos temer es a la sobrerreacción del pánico. Se manejaban unas cantidades de contagios y fallecimientos que sugerían algo de limitadas dimensiones, sin caer en la cuenta de que los números apenas permiten calcular el riesgo en los sistemas complejos. (2020, p.22).

Incluso, con la aparición de los primeros casos, estas actitudes seguían predominando y se mantenía una aparente normalidad en la mayoría de los entornos sociales, laborales, económicos e interpersonales.

Una vez el virus llega a la región, son diversas las medidas que los gobiernos adoptan para evitar poner en jaque a los distintos sistemas sociales como la salud pública, la economía y el mercado laboral, la seguridad ciudadana, la educación y la convivencia social, así como el cierre de fronteras de cada país, entre otros.

Las medidas más recurrentes iban orientadas a confinar a los ciudadanos bajo distintas figuras con distintas denominaciones pero que tenían en común la restricción de la movilidad, la "virtualización" o "remotización" de las actividades laborales y educativas que serán susceptibles de ser mudadas del entorno real al ecosistema digital. 
Este contexto planteaba una discusión sobre las libertades públicas, el uso de la información por parte de los gobiernos y el potencial riesgo de aprovechamiento de la situación para la vulneración de los derechos humanos en países cuyas democracias, antes de la pandemia ya se veían seriamente amenazadas por la desigualdad económica, los discursos de odio, la polarización política y las brechas cognitivas.

Así lo reconoce la CEPAL en su informe "América Latina y el Caribe ante la pandemia del COVID-19 Efectos económicos y sociales" (2020) donde identificaba entre otros problemas derivados de la pandemia aspectos como: disminución de las relaciones comerciales con otros países, disminución de la demanda a los servicios turísticos, contracción económica en el sector servicios (comercio, transporte, servicios empresariales, servicios sociales, etc), escasez de mano de obra, infraestructura y medicamentos para el sector salud, aumento de la brecha educativa ante la brecha digital de uso y acceso de las Tics, quiebra de las pequeñas y medianas empresas, profundización de los conflictos políticos e ideológicos, entre muchos otros aspectos.

En medio de este contexto surge la inquietud por la gestión de la comunicación de riesgo por parte de los gobiernos de América Latina. La capacidad que tiene la comunicación pública en entornos de riesgo y crisis es fundamental para modular el comportamiento individual y social, que en estos casos es una variable central para poder mitigar y contener el avance vertiginoso de la transmisión de la enfermedad en los distintos países.

Sumado a esto, el potencial que tienen las redes sociales y la penetración de la telefonía celular en la región permiten a los gobiernos poder comunicar estratégicamente a través de canales que por un lado tienen una variedad de formatos y un alcance masivo, y por el otro se prestan para la desinformación, la reproducción de noticias falsas y mitos acerca de la enfermedad y sus posibles soluciones. Así lo sostienen Aleixandre-Benavent, Castelló-Cogollos y Valderrama Zurián (2020):

Las redes sociales se han inundado de contenidos asociados al virus. A principios de abril de 2020, 113 millones de autores únicos habían compartido en Twitter mensajes sobre Covid-19 La libertad de expresión permite que las redes sociales puedan difundir cualquier información errónea no contrastada y noticias falsas Algunos mensajes son apocalípticos y producen una pandemia de miedo que acompaña a la infecciosa. En un momento en el que la cooperación es primordial, las falsedades siembran la división y reducen la solidaridad de una manera muy perniciosa $(2020, \mathrm{p} .7)$.

Igualmente, como lo plantea Macassi (2020) el reto comunicativo tenía un trasfondo cultural al plantear una transformación comportamental a sociedades acostumbradas a rutinas de socialización anclados en espacios públicos masivos y espacios privados como el familiar, el religioso y el cultural-tradicional en donde es muy común la interacción interpersonal frecuente. Al respecto Macassi afirma que estos espacios pasaban a estar "proscritos" y que "entonces, no se trata de una falta de valores, se trata de un conflicto de valores entre aquellos valores de cuidado colectivo versus los valores originado por necesidades gregarias" (Macassi 2020, p.239)

Por otra parte, el impacto de la información sobre el comportamiento y la salud mental de los ciudadanos en términos de la percepción del riesgo y sus efectos actitudinales también se convierte en una preocupación de los gobiernos en medio de su gestión. Así lo sostienen O’Brien, Moore y McNicholas (2020) que argumentan que las redes sociales han tenido dos tipos de efectos frente al comportamiento de la gente.

Por un lado un efecto positivo en tanto sirve como "conducto para la información, entregar las directivas de los gobiernos sobre la distancia social y el aislamiento, permitiendo la cercanía social a pesar de la ausencia de la proximidad física" (2020, p.52). Esto ha contribuido a un sostenimiento de la moral en situaciones críticas y se ha visto respaldado por prácticas como el "compartir imágenes, videos y status de personas que se quedan en sus casas creando un sentido de unidad y normalizando el comportamiento del aislamiento social" (2020, p.52). 
Por otro lado, el exceso de información sobre la pandemia puede llevar a que se causen "altos niveles de estrés, ansiedad y preocupación" (2020, p.52). La repetida exposición al cubrimiento de los medios eleva la alerta de las audiencias y pone a los ciudadanos en función de los efectos negativos de la pandemia casi que las 24 horas del día, capacidad que tienen los medios digitales y las redes sociales.

En ese sentido, tal ha sido el impacto del uso y manejo de la información en las redes sociales, por parte de usuarios que comparten sin ningún control y revisión los contenidos, alarmando e incitando a conductas no aconsejables frente a una situación de riesgo, como las pandemias, que la Organización Mundial de la Salud llamó, a este fenómeno, como infodemia:

Una infodemia es una sobreabundancia de información, en línea o en otros formatos, e incluye los intentos deliberados por difundir información errónea para socavar la respuesta de salud pública y promover otros intereses de determinados grupos o personas. La información errónea y falsa puede perjudicar la salud física y mental de las personas, incrementar la estigmatización, amenazar los valiosos logros conseguidos en materia de salud y espolear el incumplimiento de las medidas de salud pública, lo que reduce su eficacia y pone en peligro la capacidad de los países de frenar la pandemia. (Organización Mundial de la Salud, 2020a).

Esta reducción de eficacia se evidencia, básicamente, en la aparición de disensos frente a las políticas o programas de prevención que buscan instalar los gobiernos en la ciudadanía, con el fin de evitar la propagación de la enfermedad. Es allí cuando las instituciones públicas deberían fortalecer sus equipos de comunicación de riesgo para hacer frente, estratégicamente, no sólo a la pandemia sino también al virus de mala información que recorre las redes.

La Organización Mundial de la Salud, con justa razón afirma que la infodemia, ante la imposibilidad de eliminarla, se puede gestionar y responder consecuentemente, adaptando y evaluando nuevas prácticas con criterio científico con el objetivo de prevenir la mala información y la desinformación en la población. (Organización Mundial de la Salud, 2020b)

Garcia (2020) sostiene que

En el contexto de la Covid-19 el término se utiliza para designar los peligros del fenómeno de la desinformación durante la gestión de la pandemia, debido a que las informaciones falsas podrían acelerar la expansión de la enfermedad influenciando y fragmentando la respuesta y el comportamiento social El fenómeno de la infodemia añade, por tanto, complejidad a la actual situación, debido a los efectos no deseados que provoca, tanto en los comportamientos individuales como en los colectivos El entendimiento de la conexión entre pandemia e infodemia desde una perspectiva histórica y política resulta esencial para una mejor comprensión de la crisis del nuevo coronavirus, donde aparecen entremezclados aspectos como la bio-información, la modernidad viral y la posverdad aplicada al campo de la política (Garcia, 2020, p.2).

El problema de la infodemia agudiza para los gobiernos que implementan las estrategias de gestión del riesgo la necesidad de tomar una visión estratégica activa y propositiva para lograr los cambios comportamentales necesarios para controlar y mitigar la problemática de salud pública y sus efectos derivados. En ese orden de ideas, no solo se debe enfrentar la enfermedad sino su construcción y evolución mediatica y discursiva que queda al libre desarrollo del intercambio de mensajes en las distintas redes comunicativas, en donde las noticias falsas, la reproducción de información inexacta y la circulación de mitos y falacias "ha generado un gran problema en la salud pública, impactando negativamente la percepción frente a la salud-enfermedad, y haciendo que las poblaciones no promuevan un cambio de conducta desde el autocuidado hasta la prevención del grupo social con el que interactúan" (Cuartas-Arias, 2020, p.7).

Distintos autores han investigado a lo largo de la pandemia el manejo que los gobiernos nacionales en los diferentes países de la región le han dado a la gestión de la comunicación de riesgo (Menen- 
dez Villacreces \& Trellez-Rodriguez, 2020; Cabas, 2020; Guibara y Sanchez, 2020). Otros estudios de corte más específico han apuntado al análisis de estrategias de gestión de la comunicación de riesgo en entornos locales (Muñiz \& Cordenau, 2020; Sanchez \& Valdez, 2020; Ricard \& Medeiros, 2020; Gomez, 2020; Clunes 2020 y Mieres 2020).

La gestión de la comunicación de riesgo ha sido un tema de elevado interés dentro de la investigación en comunicación en la región. Fruto de ello es que sigan apareciendo con frecuencia investigaciones, artículos y demás publicaciones académicas que buscan dar cuenta de la forma en que los distintos gobiernos, y a través de los diferentes formatos y medio de comunicación, siguen intentando adelantar tan difícil tarea en medio de una pandemia, que antes que evidenciar síntomas de su fin se transforma permanentemente poniendo en jaque a los gobiernos en todo sentido.

El Observatorio de Medios de la Universidad de La Sabana, en medio de esta problemática decidió entrar a estudiar de qué manera los gobiernos de 12 países de América Latina estaban gestionando la comunicación de riesgo a través de la red social Facebook atendiendo a una serie de preguntas de investigación relacionadas con aspectos como ¿Cuáles son los formatos que se utilizan para la transmisión de los mensajes? ¿Sobre quién o quiénes recae la vocería de los contenidos? ¿Cuáles son los temas que componen la agenda de la comunicación de riesgo? ¿Qué recursos narrativos se utilizan para persuadir a las audiencias? ¿Cuáles son los énfasis temáticos y marcos de interpretación predominantes? y ¿Qué efecto tienen estos mensajes sobre las reacciones de las audiencias a partir de las intenciones comunicativas de los contenidos?

\section{Marco Teórico}

Como se relató en la introducción, nos proponemos investigar cómo fue el manejo de las redes sociales en el ámbito de la llegada y primeros meses de la pandemia del coronavirus en algunos países de la región de América Latina. Para ello, es indispensable abordar una serie de conceptos, que de alguna manera se articulan entre sí para entender cómo fue la estrategia discursiva y comunicacional en este periodo de tiempo.

En esa línea abordaremos, la comunicación de riesgo; el manejo de las redes sociales como una de las estrategias principales para comunicar temas en salud; la Agenda setting, para conocer cuál fue la nueva agenda pública instalada y el Framing, para saber cuál fue el enfoque y preponderancia que se le dio a la información en la llegada y primeros meses de pandemia.

Si bien, los países ya se habían enfrentado a una pandemia en el 2009 con la influenza H1N1, el Sars Cov-2 no parecía tener el mismo comportamiento. El impacto repentino que estaba causando esta enfermedad, no sólo en el individuo sino también en los estilos de vida y en las formas de gobierno, eran situaciones nunca vistas.

Se empieza a ver, entonces, la necesidad de articular esfuerzos con los ciudadanos para que todos, en conjunto, trabajen para disminuir la propagación de los contagios y tomen consciencia de las nuevas medidas que entrarían a cambiar las rutinas de vida. Ya el gobierno, no sería el único y actor principal para gestionar el cambio, sino que, estaba también en el comportamiento y actuación de los ciudadanos.

La pregunta principal de los gobiernos era entonces, cómo se debería gestionar tal información para que se fueran adquiriendo nuevos comportamientos en la ciudadanía. La respuesta era básicamente, aprender a comunicar el riesgo para que las personas modificaran sus conductas, adquiriendo nuevos hábitos.

El riesgo, se puede precisar como la percepción que una o varias personas tienen sobre el peligro. 
Percepción y peligro son los dos términos principales del riesgo y en ese sentido, la percepción se origina a partir de un hecho futuro que se observa de la realidad (Elizalde, 2009).

En ese sentido, la comunicación de riesgo se refiere entonces a la estrategia que busca reducir, mitigar o evitar vulnerabilidades en la ciudadanía. De acuerdo con esto, los riesgos, cuando ocurren, muestran la capacidad de un gobierno para gestionar el desastre, demostrando, la capacidad o fragilidad de las instituciones para hacer frente a los hechos. (Fontana, 2016).

La comunicación de riesgo se diferencia entonces de la comunicación gubernamental porque puede presentar picos de intensidad en el tiempo, concentrada, por ejemplo, en lo que son los riesgos estacionale $^{2}$ o circunstanciales. La comunicación de riesgo, por tanto, apunta principalmente a prevenir, generar conciencia o modificar hábitos o comportamientos (Riorda, 2011).

En esa medida, la comunicación, vista como una herramienta principal para generar valor social a un fenómeno determinado, debería generar empatía entre lo que se dice y a quién se dirige, pues el objetivo más importante de la comunicación de riesgo es que todos los habitantes de un mismo territorio son responsables de la colaboración en la reducción del riesgo, velando por la protección y seguridad de cada uno (Fontana, 2016).

Aunque eran pocos los riesgos que se habían presentado como generalizados en la población mundial, la Organización Panamericana de la Salud, una de las instituciones abanderadas para dar línea de acción a los Estados para enfrentar la pandemia recalcó algunos aspectos clave que se debían tener en cuenta al momento de comunicar el riesgo durante la pandemia.

Confianza y credibilidad: uno de los principios clave de la comunicación de riesgo que implica que los gobiernos siempre deben ser los primeros en dar a conocer la información que se tiene sobre el hecho ocurrido o evitable, esto implica también, reconocer la incertidumbre, aceptar que no se tiene la situación bajo control, pero mencionar todo lo que se está haciendo para lograrlo. Lo anterior lleva también a instalar la preocupación adecuada frente al hecho para que los ciudadanos sepan cómo y cuándo actuar, igualmente, invita a los gobiernos e instituciones a tener un discurso empático en donde se hable entendiendo la situación que se enfrenta. La credibilidad y la confianza en una situación de riesgo, implica también reconocer el error cuando se comete para demostrar que no se oculta información (Organización Panamericana de la Salud, 2020).

Anuncio temprano: que es una muestra de liderazgo y ayuda a salvar vidas. El anuncio temprano evita los rumores, las especulaciones y el pánico (que rara vez se llega a presentar) dentro de la población. Los anuncios tempranos, establecen expectativas en la audiencia en el corto, mediano y largo plazo y se suelen tener una estrategia discursiva de gran comprensión en la ciudadanía, evitando jergas técnicas para comunicar medidas, que en su mayoría suelen confundir a la población en vez de orientarla (Organización Panamericana de la Salud, 2020).

Transparencia que genera confianza: Detallar lo que se sabe, lo que se investiga por desconocimiento y las deficiencias de la situación. Comunicar información y medidas basadas en evidencias y técnicamente correctas (Organización Panamericana de la Salud, 2020).

Involucrar a la comunidad: si la ciudadanía no percibe el peligro, el riesgo, el miedo, no responderá de la manera más asertiva para enfrentarlo, por lo tanto, las instituciones deben hacer pública la información que afecta directamente a la población, pero también estos deben participar en la creación de mensajes basados en la experiencia y reacciones que han tenido frente a los eventos.

\footnotetext{
${ }^{2}$ Los ejemplos más claros en riesgos estacionales se ven en las temporadas de lluvias o verano con la aparición del dengue o el zika, donde la población debe extremar los cuidados y se debe generar un acompañamiento mucho más cercano de parte de las instituciones gubernamentales.
} 
Es importante, también, que los mensajes se adecúen a las creencias y tradiciones específicas de la población (Organización Panamericana de la Salud, 2020). En esto último se debe tener en cuenta que se debe aplicar el

..."principio democrático: los ciudadanos tienen el derecho a participar de las decisiones que afectan a sus vidas [y todo lo que ello implica] Principio de participación: (...) producir un público informado, involucrado, orientado a las soluciones y colaborador (...) Principio de interacción: debe estar basada en el respeto mutuo, la confianza y el intercambio abierto de información.” (Fontana, S. 2016, p. 10).

El liderazgo se convierte entonces en una herramienta indispensable para hacer frente a una situación devastadora, los ciudadanos vuelven la cara a sus líderes, alcaldes, administradores y altos funcionarios, esperando a que minimicen el daño o los saquen de este. Los líderes deben ser conscientes de que se mueven entre, afrontar las vulnerabilidades adecuadamente para mitigar el daño o bien entre la generación de una percepción errónea y la negligencia en comunicar el riesgo, en donde se marca una diferencia entre la vida y la muerte" (Boin, 2007, p. 17).

De esta manera, el trabajo mancomunado con la población se convierte en la principal estrategia de comunicación para generar alerta, prevención y modificación de conductas. De allí nace la importancia del uso de las redes sociales para comunicar y tener respuesta en tiempo real a todas las medidas instaladas desde el gobierno a la opinión pública.

Las redes sociales ofrecen un potencial enorme a los gobiernos en lo que tiene que ver con la respuesta del público, relaciones de participación con nuevas ideas y reflexiones, niveles de actividad y análisis de datos. Asimismo, permite la coordinación de esfuerzos y de capacidades humanas para que, desde la retroalimentación, se puedan plasmar y difundir políticas públicas adaptadas a las necesidades específicas de la población (Riorda \& Valenti 2016). La comunicación digital, por tanto, estimula cambios en el funcionamiento de las administraciones públicas, pues es transversal a todas las organizaciones (Riorda \& Conrero 2017) y a sus públicos ${ }^{3}$.

Reconociendo entonces la importancia de las redes sociales como una estrategia inmediata, en tiempo real y cercana con los ciudadanos, es necesario mencionar cuál debería ser, en gran medida, el contenido discursivo de los temas que se deben manejar dentro de los contenidos de la comunicación de riesgo.

La información que tiene que ver con la comunicación de riesgo, debería tener un estilo preferentemente pedagógico y comprensible. En lo posible, tendrían que ser contenidos que tengan una combinación menor con enunciados polisémicos, específicamente en lo que se refiere a las consecuencias positivas o negativas del riesgo que se quiere evitar. Igualmente, podría utilizar un eslogan o idea predominante (Riorda, 2011).

En esa línea, es necesario entender la construcción de la agenda de temas o Agenda setting, desde los medios de comunicación. "El establecimiento de agenda es un efecto sólido y extendido de la comunicación de masas, y que se deriva de contenidos concretos de los medios de comunicación." (McCombs, 2006, p. 82).

Uno de esos efectos de la Agenda setting es modificar la relevancia de los temas en la sociedad, en la medida en que van cambiando la atención de los medios de comunicación y del público. Como consecuencia de lo anterior, se da una competición entre los temas por lograr los primeros puestos en la agenda y de esa manera conseguir una mayor relevancia respecto de otros. (McCombs, 2006).

\footnotetext{
${ }^{3}$ Para ejemplificar mejor el uso de las redes sociales, como forma de comunicación de los gobiernos municipales en América Latina, cerca del 97\% tiene una cuenta oficial o institucional en Facebook; el $90 \%$ dispone de una cuenta en YouTube y el 85\% tiene una cuenta en Twitter. (Riorda \& Valenti, 2016).
} 
La frecuencia de cobertura y la jerarquía de las informaciones son dos de los factores principales porque los medios de comunicación les otorgan importancia a los temas; este aspecto es considerado como el primer nivel de la Agenda Setting. Adicionalmente, en un segundo nivel, encontramos que además de establecer la jerarquización de los temas, los medios los cubren con una serie de atributos o características, lo que permite moldear el hecho y deja entrever el punto de vista tanto de los periodistas, como del público para interpretar el tema. (Zunino, 2016).

No podemos dejar de lado, igualmente, en el marco de la comunicación de riesgo, el carácter pedagógico de la información. En la línea de la teoría de la Agenda Setting da respuesta al proceso de aprendizaje que los medios de comunicación tienen sobre los temas.

El cubrimiento y relevancia de los temas, otorgados por los medios de comunicación, permiten un aprendizaje fortuito de estos. Los medios de masas, por lo tanto, cumplen el papel de un maestro en donde, a causa de la repetición de temas, incorporan en la ciudadanía actitudes y opiniones acerca de la realidad. (McCombs, 2006).

Con lo anterior, la red es el medio más competitivo para establecer las ya mencionadas características pedagógicas en los ciudadanos. La ausencia de límites de Estado a Estado, la distribución y la gran cantidad de actores que entran en interacción da la posibilidad al usuario de seguir en detalle el variado número de lecturas que puede tener un mismo hecho. (Bozckowski, 2013).

Las noticias sobre asuntos públicos, indispensables para construir la deliberación política y para dar forma a la participación ciudadana bien informada (Bozckowski, 2013). son elementos clave en la construcción de la agenda de temas, pero también en la agenda de los atributos, que orientan, de alguna manera, las actitudes y respuestas de los ciudadanos frente a lo que el gobierno le propone.

De alguna manera, cuando los medios de comunicación plantean los temas desde un nivel de relevancia y con unos atributos específicos, están enmarcando y construyendo la interpretación de un hecho de la realidad, por la que los ciudadanos conocerán un tema específico. De allí nace la importancia, también, de hacer referencia brevemente al Framing.

El Framing puede ser entendido dentro de un paradigma crítico, cognitivo y constructivista. Para objetivos de nuestra investigación abordaremos específicamente el paradigma constructivista.

En este paradigma el Framing se ve como un proceso de construcción de la realidad, comprendido como un asunto dinámico e interactivo. En esa línea, las representaciones cobran forma por imágenes y significados inmersos en la información presentada por los medios de comunicación. Dentro de este paradigma también se considera la presentación del hecho desde las causas, los problemas y las posibles soluciones, de acuerdo con las tradiciones, cultura, contexto social y político, donde se presenta el hecho. (Koziner, 2015).

Igualmente, varios autores han notado que la forma de contar un hecho también hace parte de la construcción del Framing. En ese sentido, encontramos el Frame episódico que demuestra el rol crucial que tienen las emociones en los ciudadanos, es por ello que suele hacer el marco en un caso específico, como por ejemplo en una historia de vida; el Frame temático, por su parte, muestra los contenidos desde una perspectiva mucho más amplias y apoyándose, por ejemplo, en cifras, testimonios de expertos, etc. (Gross, 2008).

Para nuestra investigación, además, nos adherimos a los cinco nuevos frames que establecieron Semetko y Valkenburg (2000) para comprender los marcos de las publicaciones en cuanto a: frame de conflicto, que enfatiza la confrontación entre personas, grupos o instituciones; frame de interés humano, que muestra la información a través de un rostro o con una carga emocional; frame de consecuencias económicas, que enmarca los hechos a través de las consecuencias económicas que 
pueda traer a los individuos, grupos de personas o instituciones; frame de moralidad, que enmarca el tema en cuanto a prescripciones morales o religiosas y el frame de atribución de responsabilidad, en donde se atribuye la responsabilidad del hecho, como causa o consecuencia a personas, grupos o instituciones. (Semetko \& Valkenburg, 2000).

\section{Metodología}

La metodología seleccionada para la investigación fue la del análisis de contenido caracterizada por Krippendorf (1990) por su "orientación fundamentalmente empírica, exploratoria, vinculada a fenómenos reales y predictiva”. Este estudio se enmarca en lo que Piñuel Raigada (2002) denomina análisis de contenido descriptivo cuya finalidad reside en la "identificación y catalogación de la realidad empírica de los textos o documentos, mediante la definición de categorías o clases de sus elementos" (2002, p.9). Este tipo de análisis de contenido parten de

...los contextos donde se inscribe el material de análisis, es decir, de su estructura de producción o de recepción comunicativa, social y culturalmente integrada: así, por ejemplo, descripción de las características de las situaciones, entornos y contextos implicados en su producción y recepción (desde los históricos a los personales, desde los públicos a los privados), o también descripción de la estructura sociológica y psicológica que rige la conducta de los individuos, grupos o instituciones emisoras y receptoras en los procesos de comunicación que dieron origen a esos productos (Raigada, 2002, p.9).

Se seleccionaron doce casos de estudio (Tabla 1) buscando una perspectiva comparativa entre países de Suramérica y Centroamérica, así como también por la diversidad ideológica y las posturas y soluciones implementadas para hacerle frente a la Covid-19. El periodo de estudio estuvo comprendido en cada caso desde el día del primer caso confirmado en cada país hasta la fecha de corte del 30 de junio, lo que en la mayoría de los casos comprendidos tuvo un lapso de aproximadamente cuatro meses.

Tabla 1. Caracterización de los casos de estudio

\begin{tabular}{|c|c|c|c|}
\hline País & $\begin{array}{c}\text { Primer caso confirmado } \\
\text { de Covid } 19\end{array}$ & $\begin{array}{l}\text { Número de casos } \\
\text { a junio } 30 \text { de } 2020\end{array}$ & $\begin{array}{l}\text { Presidente/a vigente en el } \\
\text { periodo de estudio }\end{array}$ \\
\hline Argentina & Marzo 3 de 2020 & 64530 & Alberto Fernandez \\
\hline Bolivia & Marzo 10 de 2020 & 33219 & Jeanine Añez Chávez \\
\hline Brasil & Febrero 26 de 2020 & 1402041 & Jair Bolsonaro \\
\hline Colombia & Marzo 6 de 2020 & 97846 & Iván Duque \\
\hline Costa Rica & Marzo 6 de 2020 & 3459 & Carlos Alvarado \\
\hline Chile & Marzo 3 de 2020 & 279393 & Sebastián Piñera \\
\hline Ecuador & Febrero 29 de 2020 & 56432 & Lenin Moreno \\
\hline El Salvador & Marzo 19 de 2020 & 6438 & Nayib Bukele \\
\hline México & Febrero 27 de 2020 & 226089 & Andres Manuel Lopez Obrador \\
\hline Paraguay & Marzo 8 de 2020 & 2221 & Mario Abdo \\
\hline Perú & Marzo 6 de 2020 & 285213 & Martín Vizcarra \\
\hline Uruguay & Marzo 13 de 2020 & 936 & Luis Lacalle Pou \\
\hline
\end{tabular}

Nota: información recopilada desde la herramienta https://ourworldindata.org/coronavirus

Gracias a la plataforma Crowdtangle cuyo acceso se permitió por la convocatoria que abrió Facebook para investigadores que estuvieran adelantando estudios sobre la COVID-19, se tuvo acceso 
a todas las publicaciones emitidas por tres tipos de cuentas que se tomaron como referencia para el estudio:

1. Cuentas oficiales de los presidentes (personal),

2. Cuentas oficiales institucionales de la presidencia.

3. Cuentas del ministerio, secretaría u organizaciones encargadas de la gestión de la salud en los respectivos países.

En total se tuvieron en cuenta 36 cuentas oficiales de Facebook, tres por cada uno de los casos estudiados.

El crecimiento en el número de seguidores a lo largo de los meses que se analizaron daba un primer panorama de la dinámica que tuvieron las cuentas seleccionadas durante el periodo analizado (Tabla 2).

Tabla 2. Evolución del número de seguidores de las cuentas analizadas

\begin{tabular}{|c|c|c|c|c|c|c|c|c|c|}
\hline \multirow{2}{*}{ País } & \multicolumn{3}{|c|}{$\begin{array}{l}\text { Cuenta institucional de } \\
\text { presidencia } \\
\text { (número de seguidores) }\end{array}$} & \multicolumn{3}{|c|}{$\begin{array}{l}\text { Cuenta presidencial } \\
\text { (número de seguidores) }\end{array}$} & \multicolumn{3}{|c|}{$\begin{array}{c}\text { Cuenta ministerio/ secretaría de } \\
\text { salud } \\
\text { (número de seguidores) }\end{array}$} \\
\hline & $\begin{array}{l}\text { Día } 1 \text { de la } \\
\text { pandemia }\end{array}$ & $\begin{array}{l}30 \text { de } \\
\text { junio }\end{array}$ & $\begin{array}{c}\% \text { de } \\
\text { aumento }\end{array}$ & $\begin{array}{c}\text { Día } 1 \\
\text { de la } \\
\text { pandemia }\end{array}$ & $\begin{array}{l}30 \text { de } \\
\text { junio }\end{array}$ & $\begin{array}{c}\% \text { de } \\
\text { aumento }\end{array}$ & $\begin{array}{l}\text { Día } 1 \text { de la } \\
\text { pandemia }\end{array}$ & 30 de junio & $\begin{array}{c}\% \text { de } \\
\text { aumento }\end{array}$ \\
\hline Argentina & 1517617 & 1917789 & $26,3 \%$ & 504027 & 1023548 & $103,0 \%$ & 479979 & 1432154 & $198,3 \%$ \\
\hline Bolivia & 2423 & 31645 & $100 \%$ & 229689 & 328379 & $42,9 \%$ & 126707 & 384551 & $203,7 \%$ \\
\hline Brasil & 2007664 & 2057693 & $2,49 \%$ & 11826978 & 13449147 & $13,8 \%$ & 2201040 & 5266094 & $139,8 \%$ \\
\hline Colombia & 680877 & 1106605 & $62,5 \%$ & 1035571 & 1397328 & $34,9 \%$ & 131491 & 1660122 & $1162,5 \%$ \\
\hline $\begin{array}{l}\text { Costa } \\
\text { Rica }\end{array}$ & 280966 & 395701 & $40,8 \%$ & 407320 & 508750 & $24,9 \%$ & 211558 & 974419 & $360,5 \%$ \\
\hline Chile & 296981 & 322334 & $8,5 \%$ & 529860 & 544597 & $2,8 \%$ & 312935 & 1008330 & $222,2 \%$ \\
\hline Ecuador & 46117 & 55076 & $19,4 \%$ & 618517 & 665152 & $7,5 \%$ & 206358 & 711161 & $244,6 \%$ \\
\hline $\begin{array}{c}\text { El } \\
\text { Salvador }\end{array}$ & 232877 & 530147 & $127,6 \%$ & 2825097 & 4296186 & $52 \%$ & 116502 & 762500 & $554,5 \%$ \\
\hline México & 866260 & 2317458 & $167,5 \%$ & 7176240 & 7808182 & $8,7 \%$ & 951094 & 3671717 & $286 \%$ \\
\hline Paraguay & 200983 & 352923 & $75,6 \%$ & 538890 & 645391 & $19,7 \%$ & 155250 & 824918 & $431,3 \%$ \\
\hline Perú & 479205 & 1542126 & $221,8 \%$ & 357326 & 718079 & $101 \%$ & 559951 & 2224064 & $297,2 \%$ \\
\hline Uruguay & 56300 & 676671 & $20,2 \%$ & 150428 & 163356 & $5,8 \%$ & 45658 & 148171 & $224,5 \%$ \\
\hline
\end{tabular}

Nota: Datos extraídos de la herramienta CrowdTangle

La primera búsqueda exploratoria arrojó una cifra total de 4827 publicaciones publicadas por las 36 cuentas. Se tomó la distribución de estas publicaciones como referencia para hacer un muestreo aleatorio estratificado por país, tipo de cuenta, tipo de publicación y mes de publicación, lo que terminó configurando la siguiente muestra de 1420 noticias que fue la que finalmente se analizó (Tabla 3).

En total se analizaron 429 fotografías (30\%), 389 ilustraciones (27\%), 369 videos de Facebook (26\%), 128 enlaces (9\%) 63 álbumes fotográficos (9\%), 36 status (3\%) y 6 Facebook Live (1\%).

Una vez seleccionada la muestra se construyó una matriz de análisis de contenidos en donde se registraron dos tipos de datos. Por una parte, las métricas de interacción y reacciones de las publicaciones, datos que brinda la plataforma Crowdtangle y que permiten ver la interactividad y el 
impacto del contenido en la audiencia. Por otra parte, se registraron datos derivados de variables teóricas operacionalizadas para analizar la agenda temática, el framing, la intención emocional de la comunicación, la comunicación de riesgo y los actores presentes en los mensajes.

Tabla 3. Composición de la muestra

\begin{tabular}{|c|c|c|}
\hline \multicolumn{1}{|c|}{ País } & Frecuencia & Porcentaje \\
\hline México & 280 & $20 \%$ \\
\hline Costa Rica & 177 & $12 \%$ \\
\hline Chile & 158 & $11 \%$ \\
\hline Ecuador & 158 & $11 \%$ \\
\hline Colombia & 145 & $10 \%$ \\
\hline Paraguay & 127 & $9 \%$ \\
\hline El Salvador & 95 & $7 \%$ \\
\hline Bolivia & 87 & $6 \%$ \\
\hline Brasil & 79 & $6 \%$ \\
\hline Argentina & 58 & $4 \%$ \\
\hline Uruguay & 40 & $3 \%$ \\
\hline Perú & 16 & $1 \%$ \\
\hline
\end{tabular}

Nota: Elaboración propia

Las publicaciones fueron analizadas por un equipo de 8 auxiliares de investigación del Observatorio de Medios de la Universidad de la Sabana previa prueba de validación inter codificadores.

\section{Resultados}

La investigación tuvo cuatro grandes intereses. Primero la identificación de las vocerías y los formatos utilizados desde la red social Facebook para gestionar la comunicación de riesgo. Segundo, la construcción del mensaje desde la perspectiva de las teorías de la opinión pública y la comunicación política, es decir la determinación de la agenda, los énfasis temáticos, los marcos de interpretación y los tipos de mensajes de gestión del riesgo. Tercero, los recursos de persuasión emocional utilizados y cuarto los actores presentes en la construcción de los mensajes. A continuación, se presentan los principales resultados de cada una de estas temáticas

\subsection{Emisores y formatos}

La primera inquietud de investigación apuntaba hacia la identificación de los emisores de los mensajes y los formatos de emisión de estos. La comunicación relacionada con la COVID-19 en el marco de la pandemia se emitió, en Facebook, desde una perspectiva general, principalmente desde las cuentas de los organismos encargados de la salud pública en los distintos países en un $66 \%$ de las publicaciones, seguido de un $25 \%$ desde las cuentas institucionales de la presidencia y solo un $11 \%$ desde las cuentas personales de los/as presidentes/as.

Al explorar comparativamente se encuentran evidencias importantes en las cuentas emisoras del mensaje (Gráfico 1).

En la mayoría de los países los mensajes relacionados con la gestión de la COVID-19 se originaron desde las cuentas de los organismos encargados de la salud pública. Es el caso de Uruguay, Paraguay, Chile, México, El Salvador y Bolivia. Países como Colombia, Costa Rica, Brasil, Perú 
y Argentina tuvieron un volumen más alto de emisión desde las cuentas institucionales de la presidencia. Es interesante destacar que en los casos de Brasil, Colombia, El Salvador, Perú, Bolivia y Argentina hay un porcentaje significativo de mensajes originados desde las cuentas personales de los/as presidentes/as.

Gráfico 1. Comparativo cuentas emisoras de los contenidos por país

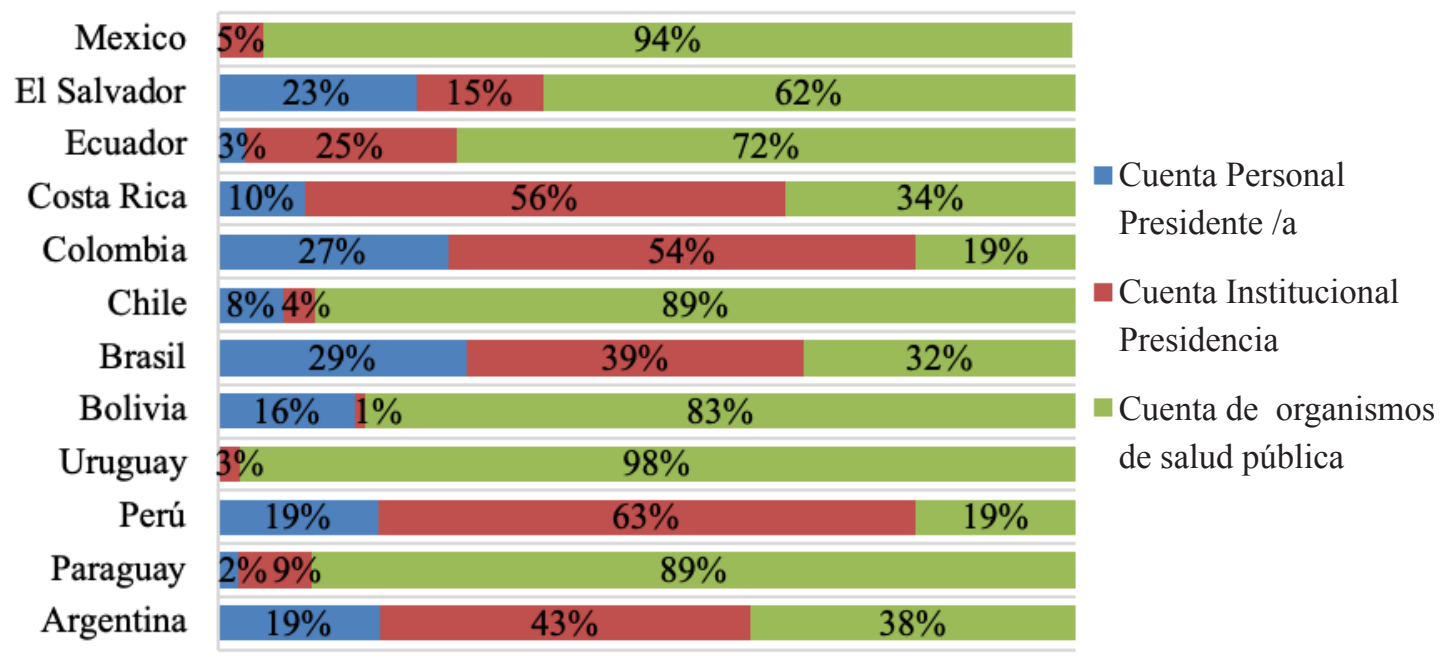

Fuente: elaboración propia

Con respecto a los formatos, al desagregar los registros por país se encuentran diferencias que permiten evidenciar diferentes estrategias de gestión de la información (Tabla 4).

Tabla 4. Distribución de los formatos por país

\begin{tabular}{|l|c|c|c|c|c|c|c|}
\hline \multirow{2}{*}{ País } & \multicolumn{7}{|c|}{ Tipo de contenido } \\
\cline { 2 - 8 } & Álbum & Enlace & FB Live & FB Video & Foto & Ilustración & Status \\
\hline Argentina & $12 \%$ & $0 \%$ & $0 \%$ & $50 \%$ & $26 \%$ & $12 \%$ & $0 \%$ \\
\hline Bolivia & $2 \%$ & $5 \%$ & $2 \%$ & $18 \%$ & $48 \%$ & $24 \%$ & $0 \%$ \\
\hline Brasil & $1 \%$ & $3 \%$ & $0 \%$ & $15 \%$ & $65 \%$ & $0 \%$ & $16 \%$ \\
\hline Chile & $0 \%$ & $1 \%$ & $2 \%$ & $42 \%$ & $55 \%$ & $1 \%$ & $0 \%$ \\
\hline Colombia & $0 \%$ & $1 \%$ & $0 \%$ & $37 \%$ & $42 \%$ & $19 \%$ & $0 \%$ \\
\hline Costa Rica & $1 \%$ & $50 \%$ & $0 \%$ & $12 \%$ & $5 \%$ & $23 \%$ & $9 \%$ \\
\hline Ecuador & $11 \%$ & $3 \%$ & $0 \%$ & $27 \%$ & $15 \%$ & $45 \%$ & $0 \%$ \\
\hline El Salvador & $0 \%$ & $12 \%$ & $0 \%$ & $6 \%$ & $77 \%$ & $0 \%$ & $5 \%$ \\
\hline México & $6 \%$ & $0 \%$ & $0 \%$ & $39 \%$ & $3 \%$ & $52 \%$ & $0 \%$ \\
\hline Paraguay & $2 \%$ & $2 \%$ & $1 \%$ & $7 \%$ & $39 \%$ & $48 \%$ & $1 \%$ \\
\hline Perú & $0 \%$ & $0 \%$ & $0 \%$ & $25 \%$ & $69 \%$ & $0 \%$ & $6 \%$ \\
\hline Uruguay & $35 \%$ & $30 \%$ & $0 \%$ & $3 \%$ & $0 \%$ & $33 \%$ & $0 \%$ \\
\hline
\end{tabular}

Nota: Elaboración propia

Los formatos más recurrentes son las fotografías, las ilustraciones y los videos incrustados en Facebook. Formatos como el Facebook Live y los status aparecen de manera marginal. 


\subsection{El mensaje}

Ahora bien, al entrar a analizar los componentes de los mensajes se buscó determinar en primera instancia la composición de la agenda temática de la comunicación de gobierno orientada a la gestión de la pandemia (Gráfico 2).

Gráfico 2. Agenda temática: perspectiva regional

Recomendaciones de autocuidado y cuidado colectivo
Apelaciones a aspectos culturales y emocionales
Infraestructura y recursos del sector salud
Restricciones de libertades y derechos
Rasgos cientificos y epidemiologicos COVID 19
Auxilios a poblaciones vulnerables

Efectos del comportamiento social sobre la pandemia

Protocolos de bioseguridad

Auxilios economicos a PYMES y grandes empresas

Manejo de orden público y la seguridad ciudadana

Contenidos motivacionales

Sector transporte

Salud mental y psicologica

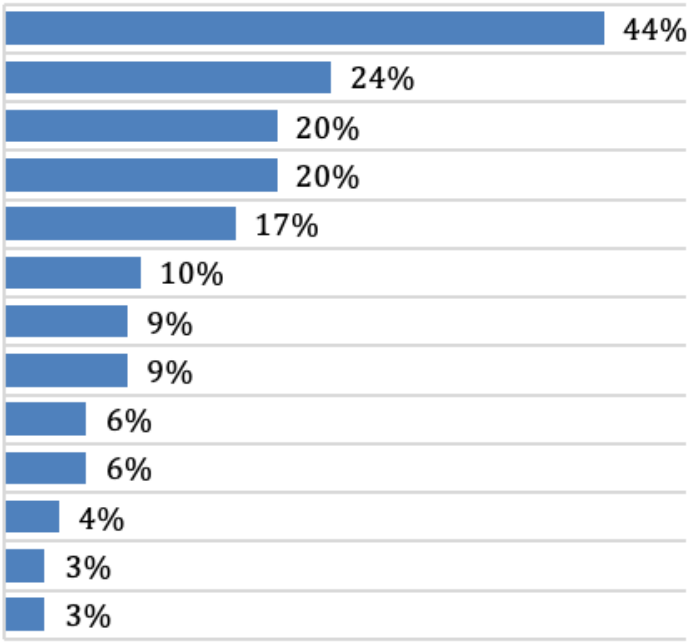

Fuente: elaboración propia

El tema principal tiene que ver con mensajes relacionados con el autocuidado y el cuidado colectivo. Un poco menos de la mitad de las publicaciones contenían recomendaciones relacionadas con prácticas como el lavado de manos, desinfección de alimentos y superficies, distancia social, etc.

Aparece un número importante de mensajes de carácter más específico y que adquieren sentido en los contextos particulares apelando a emociones, referentes culturales y símbolos nacionales como mecanismos de persuasión y movilización.

Igualmente, en un $20 \%$ de los mensajes se hace referencia a medidas tomadas para la restricción de derechos y libertades en aras de garantizar la salud pública (cuarentenas, restricciones de movilidad, alternancia, entre otros).

Así mismo, otro $20 \%$ son publicaciones que informan sobre la evolución cuantitativa de las cifras de la pandemia (contagios, casos activos, recuperados, muertos).

Otros temas que aparecen con menor frecuencia se relacionan con ayudas económicas, manejo de orden público, protocolos para actividades socioeconómicas, manejo de la salud mental, etc.

Al desagregar la información podemos encontrar las agendas particulares de cada gobierno.

En la Tabla 5 se destacan los cinco temas principales de cada uno de los gobiernos en sus publicaciones de Facebook. 
Tabla 5. Agenda temática por gobierno

\begin{tabular}{|c|c|c|c|c|c|}
\hline País & Tema 1 & Tema 2 & Tema 3 & Tema 4 & Tema 5 \\
\hline Argentina & $\begin{array}{l}\text { Apelaciones a va- } \\
\text { lores y referentes } \\
\text { culturales }\end{array}$ & $\begin{array}{l}\text { Protocolos de } \\
\text { bioseguridad para } \\
\text { actividades so- } \\
\text { cioeconómicas }\end{array}$ & $\begin{array}{c}\text { Recomendaciones } \\
\text { para el autocuidado } \\
\text { y el cuidado colec- } \\
\text { tivo }\end{array}$ & $\begin{array}{l}\text { Infraestructura, } \\
\text { recursos sector } \\
\text { salud }\end{array}$ & $\begin{array}{l}\text { Restricciones de } \\
\text { libertades y dere- } \\
\text { chos ciudadanos }\end{array}$ \\
\hline Bolivia & $\begin{array}{l}\text { Cifras de la pan- } \\
\text { demia (contagios, } \\
\text { muertos, recupe- } \\
\text { rados, etc.) }\end{array}$ & $\begin{array}{l}\text { Infraestructura, } \\
\text { recursos sector } \\
\text { salud }\end{array}$ & $\begin{array}{c}\text { Recomendaciones } \\
\text { para el autocuidado } \\
\text { y el cuidado colec- } \\
\text { tivo }\end{array}$ & $\begin{array}{l}\text { Restricciones } \\
\text { de libertades y } \\
\text { derechos ciu- } \\
\text { dadanos }\end{array}$ & $\begin{array}{l}\text { Rasgos cientí- } \\
\text { ficos y epide- } \\
\text { miológicos del } \\
\text { COVID19 }\end{array}$ \\
\hline Brasil & $\begin{array}{l}\text { Infraestructura, } \\
\text { recursos sector } \\
\text { salud }\end{array}$ & $\begin{array}{c}\text { Auxilios económi- } \\
\text { cos a PYMES y } \\
\text { grandes empre- } \\
\text { sas }\end{array}$ & $\begin{array}{l}\text { Auxilios a poblacio- } \\
\text { nes vulnerables }\end{array}$ & $\begin{array}{l}\text { Apelaciones } \\
\text { a valores y } \\
\text { referentes cul- } \\
\text { turales }\end{array}$ & $\begin{array}{c}\text { Recomenda- } \\
\text { ciones para el } \\
\text { autocuidado y el } \\
\text { cuidado colectivo }\end{array}$ \\
\hline Colombia & $\begin{array}{l}\text { Recomenda- } \\
\text { ciones para el } \\
\text { autocuidado y el } \\
\text { cuidado colectivo }\end{array}$ & $\begin{array}{l}\text { Apelaciones a va- } \\
\text { lores y referentes } \\
\text { culturales }\end{array}$ & $\begin{array}{l}\text { Restricciones de } \\
\text { libertades y dere- } \\
\text { chos ciudadanos }\end{array}$ & $\begin{array}{l}\text { Manejo del } \\
\text { orden público } \\
\text { y la seguridad } \\
\text { ciudadana }\end{array}$ & $\begin{array}{l}\text { Protocolos de } \\
\text { bioseguridad } \\
\text { para actividades } \\
\text { socioeconómicas }\end{array}$ \\
\hline $\begin{array}{c}\text { Costa } \\
\text { Rica }\end{array}$ & $\begin{array}{l}\text { Apelaciones a va- } \\
\text { lores y referentes } \\
\text { culturales }\end{array}$ & $\begin{array}{l}\text { Cifras de la pan- } \\
\text { demia (contagios, } \\
\text { muertos, recupe- } \\
\text { rados, etc.) }\end{array}$ & $\begin{array}{l}\text { Infraestructura, } \\
\text { recursos sector } \\
\text { salud }\end{array}$ & $\begin{array}{l}\text { Auxilios eco- } \\
\text { nómicos a PY- } \\
\text { MES y grandes } \\
\text { empresas }\end{array}$ & $\begin{array}{l}\text { Auxilios a pobla- } \\
\text { ciones vulnera- } \\
\text { bles }\end{array}$ \\
\hline Chile & $\begin{array}{l}\text { Recomenda- } \\
\text { ciones para el } \\
\text { autocuidado y el } \\
\text { cuidado colectivo }\end{array}$ & $\begin{array}{l}\text { Restricciones de } \\
\text { libertades y dere- } \\
\text { chos ciudadanos }\end{array}$ & $\begin{array}{l}\text { Apelaciones a va- } \\
\text { lores y referentes } \\
\text { culturales }\end{array}$ & $\begin{array}{l}\text { Rasgos cientí- } \\
\text { ficos y epide- } \\
\text { miológicos del } \\
\text { COVID19 }\end{array}$ & $\begin{array}{l}\text { Salud mental y } \\
\text { psicológica }\end{array}$ \\
\hline Ecuador & $\begin{array}{l}\text { Apelaciones a va- } \\
\text { lores y referentes } \\
\text { culturales }\end{array}$ & $\begin{array}{l}\text { Cifras de la pan- } \\
\text { demia (contagios, } \\
\text { muertos, recupe- } \\
\text { rados, etc.) }\end{array}$ & $\begin{array}{c}\text { Recomendaciones } \\
\text { para el autocuidado } \\
\text { y el cuidado colec- } \\
\text { tivo }\end{array}$ & $\begin{array}{l}\text { Restricciones } \\
\text { de libertades y } \\
\text { derechos ciu- } \\
\text { dadanos }\end{array}$ & $\begin{array}{c}\text { Protocolos de } \\
\text { bioseguridad } \\
\text { para actividades } \\
\text { socioeconómicas }\end{array}$ \\
\hline $\begin{array}{l}\text { El Salva- } \\
\text { dor }\end{array}$ & $\begin{array}{l}\text { Recomenda- } \\
\text { ciones para el } \\
\text { autocuidado y el } \\
\text { cuidado colectivo }\end{array}$ & $\begin{array}{l}\text { Cifras de la pan- } \\
\text { demia (contagios, } \\
\text { muertos, recupe- } \\
\text { rados, etc.) }\end{array}$ & $\begin{array}{l}\text { Infraestructura, } \\
\text { recursos sector } \\
\text { salud }\end{array}$ & $\begin{array}{l}\text { Apelaciones } \\
\text { a valores y } \\
\text { referentes cul- } \\
\text { turales }\end{array}$ & $\begin{array}{l}\text { Restricciones de } \\
\text { libertades y dere- } \\
\text { chos ciudadanos }\end{array}$ \\
\hline México & $\begin{array}{l}\text { Recomenda- } \\
\text { ciones para el } \\
\text { autocuidado y el } \\
\text { cuidado colectivo }\end{array}$ & $\begin{array}{l}\text { Rasgos científicos } \\
\text { y epidemiológicos } \\
\text { del COVID19 }\end{array}$ & $\begin{array}{l}\text { Cifras de la pan- } \\
\text { demia (contagios, } \\
\text { muertos, recupera- } \\
\text { dos, etc.) }\end{array}$ & $\begin{array}{c}\text { Restricciones } \\
\text { de libertades y } \\
\text { derechos ciu- } \\
\text { dadanos }\end{array}$ & $\begin{array}{l}\text { Infraestructura, } \\
\text { recursos sector } \\
\text { salud }\end{array}$ \\
\hline Paraguay & $\begin{array}{l}\text { Cifras de la pan- } \\
\text { demia (contagios, } \\
\text { muertos, recupe- } \\
\text { rados, etc.) }\end{array}$ & $\begin{array}{l}\text { Infraestructura, } \\
\text { recursos sector } \\
\text { salud }\end{array}$ & $\begin{array}{c}\text { Recomendaciones } \\
\text { para el autocuidado } \\
\text { y el cuidado colec- } \\
\text { tivo }\end{array}$ & $\begin{array}{l}\text { Apelaciones } \\
\text { a valores y } \\
\text { referentes cul- } \\
\text { turales }\end{array}$ & $\begin{array}{l}\text { Restricciones de } \\
\text { libertades y dere- } \\
\text { chos ciudadanos }\end{array}$ \\
\hline Perú & $\begin{array}{l}\text { Recomenda- } \\
\text { ciones para el } \\
\text { autocuidado y el } \\
\text { cuidado colectivo }\end{array}$ & $\begin{array}{l}\text { Restricciones de } \\
\text { libertades y dere- } \\
\text { chos ciudadanos }\end{array}$ & $\begin{array}{l}\text { Cifras de la pan- } \\
\text { demia (contagios, } \\
\text { muertos, recupera- } \\
\text { dos, etc.) }\end{array}$ & $\begin{array}{l}\text { Efectos de cier- } \\
\text { tos comporta- } \\
\text { mientos sobre } \\
\text { la pandemia }\end{array}$ & $\begin{array}{c}\text { Protocolos de } \\
\text { bioseguridad } \\
\text { para actividades } \\
\text { socioeconómicas }\end{array}$ \\
\hline Uruguay & $\begin{array}{l}\text { Apelaciones a va- } \\
\text { lores y referentes } \\
\text { culturales }\end{array}$ & $\begin{array}{l}\text { Recomenda- } \\
\text { ciones para el } \\
\text { autocuidado y el } \\
\text { cuidado colectivo }\end{array}$ & $\begin{array}{l}\text { Cifras de la pan- } \\
\text { demia (contagios, } \\
\text { muertos, recupera- } \\
\text { dos, etc.) }\end{array}$ & $\begin{array}{l}\text { Salud mental y } \\
\text { psicológica }\end{array}$ & $\begin{array}{l}\text { Protocolos de } \\
\text { bioseguridad } \\
\text { para actividades } \\
\text { socioeconómicas }\end{array}$ \\
\hline
\end{tabular}

Nota: Elaboración propia

Para ahondar un poco más en la interpretación de estas agendas se hizo un análisis a la forma de abordar cada uno de estos temas identificando el énfasis interpretativo. De entrada es claro que más de la mitad de las publicaciones, el 53\% se enmarcaron desde una perspectiva netamente de salud 
pública, seguido de un énfasis gubernamental con un 19\% en donde la interpretación apuntaba a poner los ojos sobre la gestión pública del gobierno más allá de los temas. Un $15 \%$ de las publicaciones tenían un énfasis de carácter social y tan solo un $4 \%$ tenían énfasis de carácter judicial y político respectivamente.

Revisando el uso de los énfasis en los casos particulares (Tabla 6) se encuentra que en la mayoría de los casos predomina el énfasis de salud pública, seguido del gubernamental. En algunos países como Colombia y El Salvador aparece el énfasis social en un $28 \%$ y $26 \%$ respectivamente. En Chile el énfasis jurídico/legal tiene un $21 \%$.

Tabla 6. Énfasis por gobierno

\begin{tabular}{|c|c|c|c|c|c|c|c|}
\hline \multirow{2}{*}{ País } & \multicolumn{7}{|c|}{ Énfasis } \\
\cline { 2 - 9 } & Cultural & Económico & Gubernamental & Jurídico /legal & Político & Salud & Social \\
\hline Argentina & $0 \%$ & $0 \%$ & $26 \%$ & $12 \%$ & $14 \%$ & $33 \%$ & $16 \%$ \\
\hline Bolivia & $1 \%$ & $1 \%$ & $8 \%$ & $0 \%$ & $7 \%$ & $79 \%$ & $3 \%$ \\
\hline Brasil & $0 \%$ & $5 \%$ & $28 \%$ & $3 \%$ & $6 \%$ & $39 \%$ & $19 \%$ \\
\hline Chile & $0 \%$ & $0 \%$ & $9 \%$ & $21 \%$ & $0 \%$ & $66 \%$ & $3 \%$ \\
\hline Colombia & $1 \%$ & $12 \%$ & $21 \%$ & $2 \%$ & $0 \%$ & $37 \%$ & $28 \%$ \\
\hline Costa Rica & $2 \%$ & $9 \%$ & $23 \%$ & $1 \%$ & $6 \%$ & $44 \%$ & $16 \%$ \\
\hline Ecuador & $0 \%$ & $2 \%$ & $27 \%$ & $6 \%$ & $11 \%$ & $39 \%$ & $15 \%$ \\
\hline El Salvador & $0 \%$ & $6 \%$ & $20 \%$ & $1 \%$ & $6 \%$ & $37 \%$ & $29 \%$ \\
\hline México & $0 \%$ & $1 \%$ & $11 \%$ & $0 \%$ & $1 \%$ & $73 \%$ & $14 \%$ \\
\hline Paraguay & $0 \%$ & $2 \%$ & $20 \%$ & $0 \%$ & $3 \%$ & $65 \%$ & $9 \%$ \\
\hline Perú & $0 \%$ & $0 \%$ & $31 \%$ & $0 \%$ & $6 \%$ & $56 \%$ & $6 \%$ \\
\hline Uruguay & $0 \%$ & $0 \%$ & $48 \%$ & $0 \%$ & $0 \%$ & $50 \%$ & $3 \%$ \\
\hline
\end{tabular}

Nota: Elaboración propia

Con respecto al frame narrativo se ve un fuerte predominio de los frames temáticos (88\%) sobre los episódicos (12\%). Esto puede deberse a un abordaje más técnico y científico de la información, las vocerías seleccionadas y la incertidumbre de los primeros meses de la pandemia. Si analizamos esto en los casos específicos encontramos el siguiente panorama (Gráfico 3).

Gráfico 3. Frame narrativo: perspectiva regional

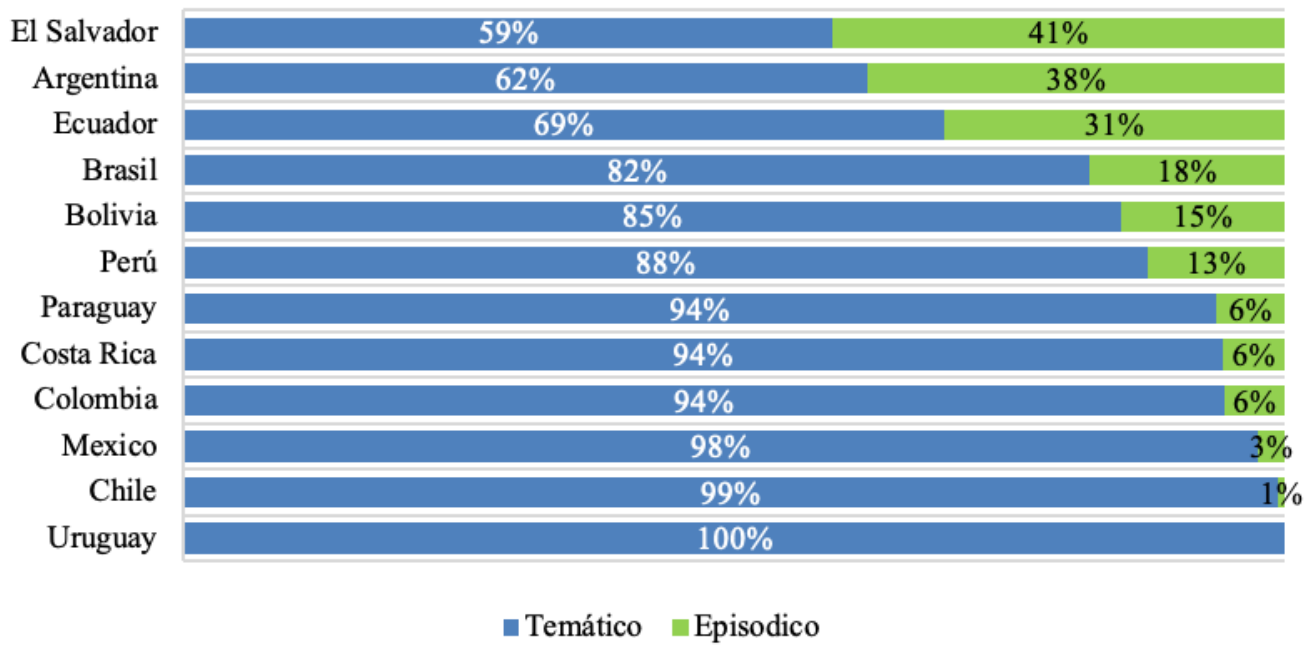

Fuente: elaboración propia 
Los países que más incorporan un frame narrativo episódico son El Salvador, Argentina y Ecuador. Por su parte Uruguay, Chile y México son los que utilizan de manera mayoritaria el frame temático.

Ahora bien, con relación a la comunicación de riesgo se buscó identificar la existencia de mensajes enfocados estratégicamente desde esta perspectiva. Acudiendo a la teoría de Covello y Sandman (2011) de las etapas de la comunicación de riesgo se determinaron tres tipos de mensajes: llamados a la calma, llamados al cuidado y llamados a la resiliencia (Tabla 7). Adicionalmente se incluyó la categoría "informativo" para aquellos contenidos que no tenían una orientación estratégica evidente y tenían una naturaleza netamente informativa. El 44\% de las publicaciones eran netamente informativas, el 39\% llamados al cuidado, el 12\% llamado a la calma y solo el $4 \%$ llamados a la resiliencia.

Tabla 7. Países que utilizan más las distintas formas de comunicación de riesgo

\begin{tabular}{|c|c|c|c|c|c|}
\multicolumn{2}{|c|}{ Llamados a la calma } & \multicolumn{2}{|c|}{ Llamados a la resiliencia } & \multicolumn{2}{|c|}{ Llamados al cuidado } \\
\hline Brasil & $29 \%$ & Perú & $13 \%$ & Chile & $75 \%$ \\
\hline Colombia & $25 \%$ & Chile & $9 \%$ & Perú & $69 \%$ \\
\hline Ecuador & $24 \%$ & Argentina & $9 \%$ & México & $54 \%$ \\
\hline Argentina & $22 \%$ & El Salvador & $8 \%$ & Argentina & $47 \%$ \\
\hline Bolivia & $16 \%$ & Bolivia & $8 \%$ & El Salvador & $41 \%$ \\
\hline
\end{tabular}

Fuente: elaboración propia

En la mayoría de los países primaron mensajes de llamado al cuidado, especialmente en aquellos donde los contagios escalaron de manera mas rápida y los gobiernos implementaron estrategias de prevención como Chile y Perú. En países como Brasil y Colombia, donde aparecen más altos los llamados a la calma, los primeros abordajes comunicativos, especialmente desde los discursos presidenciales apuntaban a posiciones más laxas frente a la llegada del virus. Incluso en el caso de Brasil, su presidente mantuvo una postura escéptica e incluso llamaba a sus ciudadanos a no creer en el virus y seguir con su vida común y corriente.

\section{Discusión y conclusiones}

La pandemia supuso para los gobiernos de todo el mundo un reto en términos de gestión de crisis, en este caso específico la gestión de la comunicación de crisis. Si bien la pandemia no se desarrolló de la misma manera en los distintos países si se encuentra un factor común y fue la incapacidad de anticipar un fenómeno que ya había ocurrido en otras regiones del mundo, con la salvedad que muchos de los países analizados tienen serias problemáticas sociales, económicas y políticas que también dificultan tener una acción más eficiente frente a la pandemia.

Una de esas problemáticas tiene que ver con los procesos de comunicación gubernamental que surgen en la mayoría de los países con liderazgos de carácter populista y en algunos casos gobernantes con prácticas autoritarias y con posiciones, inicialmente, escépticas frente a la existencia del virus y las formas de mitigarlo.

Uno de los canales de comunicación entre el gobierno y la ciudadanía más utilizado en el marco de la pandemia son las redes sociales, entre ellas Facebook.

Es importante recalcar que el análisis hecho en este estudio está delimitado a la red social Facebook y no es generalizable a la estrategia integral de comunicaciones de ninguno de los gobiernos analizados, sin embargo si permite hacer algunas inferencias acerca de la estrategia digital de comuni- 
cación de riesgo, incluso en algunos casos desmitificando impresiones que quedan del manejo de la pandemia luego de ver los mensajes y los discursos de los gobernantes en los medios tradicionales.

Es interesante encontrar que en la mayoría de los casos los mensajes de la comunicación de riesgo se emitieron desde las cuentas institucionales de los organismos encargados del sector salud. Además, un alto porcentaje de estos mensajes se construyen desde una perspectiva narrativa temática (Gross, 2008) lo que permite evidenciar un esfuerzo por enfocarse en la pedagogía y el cambio de hábitos comportamentales frente al virus para mitigar el impacto del virus. Esto supone un reto en términos de la resonancia cultural de la comunicación, ya que no por publicar más sobre determinados temas esto puede generar un cambio de comportamiento de manera automática.

Pareciera existir una diferencia sustancial en las estrategias de comunicación digitales y las no digitales. En la primera hay un mayor interés por volcar toda la comunicación de riesgo hacia las cuestiones pedagógicas con un enfoque de salud pública, mientras que en los medios tradicionales muchos de los presidentes tienen la presencia que en redes delegan a los expertos temáticos, construyendo un discurso de corte más político y aprovechando la pandemia para sacar adelante sus propuestas de gobierno e intereses electorales futuros.

En cuanto a la agenda de temas, vista desde la comunicación de riesgo, se hubiera supuesto que las Recomendaciones para el autocuidado y el cuidado colectivo y los Protocolos de bioseguridad para actividades socioeconómicas, se instalaran como los primeros temas en las agendas de América Latina. Esto además, porque ya se contaba con un contexto previo a la actuación de países asiáticos y europeos, en donde se activaron desde un primer momento, estas medidas.

Cinco de los doce países analizados instalaron en su primer tema de agenda las Recomendaciones al autocuidado. Llama la atención, el caso de Brasil, en donde este tema fue el quinto de la agenda; si se analiza en contexto, este país aplicó alguna de las posibles reacciones ligadas a los riesgos, cuando estos se presentan: negación, apatía o transformación (Beck, en Elizalde, H. 2009) en donde desde el presidente prestaba poca importancia al riesgo verdadero que podría traer el Covid-19 a los individuos y al sistema de salud, mostrando de esa manera apatía por algunas medidas de bioseguridad. Esto podría explicar, en cierta manera, que haya sido el país que logró superar el millón de contagios en cuatro meses desde la llegada del virus a su territorio.

En el caso de México, que también desde el ejecutivo se mostraron esa serie de posibles reacciones, es notorio observar que, aunque el tema de Protocolos de bioseguridad no llegó a ocupar los cinco primeros temas de la agenda, sí se instaló como el número uno, las Recomendaciones al autocuidado.

Sin embargo, el caso peruano también es notorio, porque a pesar de haber instalado en la agenda las recomendaciones para el autocuidado y los Protocolos de bioseguridad, en el primer y quinto puesto, respectivamente, hayan tenido, después de Brasil, la mayor cantidad de contagios de la región, desde el anuncio del primer caso hasta junio de 2020.

Lo anterior demuestra la efectividad que tuvo en la mayoría de la población, los anuncios de la comunicación de riesgo, enmarcados en la modificación de hábitos y conductas, encaminadas a la prevención, pero no deja de llamar la atención el caso peruano que, tal vez, puede responder las altas tasas de contagio desde una perspectiva social y económica, propia de ese país.

Por otra parte, se demuestra también la importancia que la población de cada país dio a las redes sociales como fuente de información inmediata y a tiempo real. El crecimiento de seguidores a las cuentas personales de los presidentes, cuentas de ministerios/secretarías de salud, es notorio, pues 
la mayoría logró aumentar en un número significativo a sus seguidores. El caso más notorio es el caso colombiano con la cuenta del Ministerio de Salud que tuvo un aumento de más de un millón de seguidores, con un porcentaje total de incremento de $1162 \%$.

Ante la necesidad de información y pedagogía frente a la pandemia cada vez más las redes se constituyen como espacios de difusión privilegiados por los gobiernos para los discursos racionales a través de los organismos técnicos, sin embargo es válido preguntarse si las audiencias en estos medios está esperando este tipo de contenidos y si el sentido de los mensajes esta teniendo el efecto deseado del cambio comportamental o simplemente se está quedando en una visión mas informativa y menos estratégica de la comunicación de riesgo.

\section{Bibliografía}

Aleixandre-Benavent, R., Castelló-Cogollos, L., \& Valderrama-Zurián, J. C. (2020). Información y comunicación durante los primeros meses de Covid-19. Infodemia, desinformación y papel de los profesionales de la información. El profesional de la información (EPI), 29(4).

Boin, A. (2007). La política de la gestión de crisis: el liderazgo público bajo presión. INAP.

Bozckowski, P. (2013). Preferencias divergentes de los lectores y de los periodistas en las noticias on-line. CIC. Cuadernos De Información Y Comunicación, 18, 51-55.

Cabás, P. (2020). Gestión de la Comunicación de crisis del COVID-19 en la isla de Tierra del Fuego, Argentina. Revista ComHumanitas, 11(3), 96-125.

CEPAL (2020). América Latina y el Caribe ante la pandemia del COVID-19: efectos económicos $y$ sociales.

Clunes Clunes, R. (2020). Pandemia Covid-19 en Chile. Question/Cuestión, 1(mayo), e323. https://doi.org/10.24215/16696581e323

Covello, V. \& Sandman, P. M. (2011). Risk communication: evolution and revolution. Solutions to an Environment in Peril, 164, 178.

Cuartas-Arias, M. (2020). Enfrentando la pandemia: la infodemia en la COVID-19. International Journal of Psychological Research, 13(2), 6.

Elizalde, L. H. (2009). Gestión de la comunicación pública: empresas, grupos e instituciones en el escenario público. Bosch.

Fontana, S. E. (2016). ¿Se puede hacer algo frente al riesgo de desastres?, ¿comunicar el riesgo o el riesgo de comunicar? Más poder local, (29), 8-10.

García-Marín, D. (2020). Infodemia global. Desórdenes informativos, narrativas fake y factchecking en la crisis de la Covid-19//Global infodemic: Information disorders, false narratives, and fact checking during the Covid-19 crisis. Profesional de la información, 29(4).

Gómez, C. D. E. (2020). La paradoja pandémica de la comunicación política en Chile. Más poder local, (41), 28-30.

Gross, K. (2008). Framing Persuasive Appeals: Episodic and Thematic Framing, Emotional Response, and Policy Opinion. Political Psychology, 29: 169-192. https://doi.org/10.1111/j.14679221.2008.00622.x

Innerarity, D. (2020). Pandemocracia: una filosofía de la crisis del coronavirus. Galaxia Gutenberg. 
Koziner, N. S. (2015). El framing: un programa investigación para el estudio de las comunicaciones mediáticas. Animus. Revista Interamericana de Comunicação Midiática, 14(28).

Krippendorff, K. (1990). Metodología de análisis de contenido, teoría y práctica. Paidos.

Macassi, S. (2020). Comunicación para el cambio de comportamientos y estrategias sanitaria del gobierno peruano frente al COVID-19. Chasqui: Revista Latinoamericana de Comunicación, (145), 235-258.

McCombs, M. (2006). Estableciendo la agenda. El impacto de los medios en la opinión pública y en el conocimiento. Paidos

Menéndez Villacreces, M., Trelles Rodríguez, I., Badia Valdés, A. T., \& Donoso, F. (2020). Reflexiones en torno a la gestión de la comunicación de riesgos a propósito de la COVID-19. Alcance, 9(24), 128-148.

Mieres, P. (2020). La comunicación gubernamental de la crisis en tiempos del coronavirus: el caso de Uruguay. Más poder local, (42), 36-41.

Muñiz, C., \& Corduneanu, V. I. (2020). Percepción de riesgo y consumo mediático durante el inicio de la pandemia de COVID-19 en México. Más poder local, (41), 44-47.

O’Brien, M., Moore, K., \& McNicholas, F. (2020). Social Media Spread During Covid-19: The Pros and Cons of Likes and Shares. Irish medical journal, 113(4), 52.

Organización Mundial de la Salud. (2020a, 09 23). Gestión de la infodemia sobre la COVID-19:

Promover comportamientos saludables y mitigar los daños lderivados de la información incorrecta y falsa. Organización Mundial de la Salud. Comunicados de prensa. https://www.who.int/es/ news/item/23-09-2020-managing-the-covid-19-infodemic-promoting-healthy-behaviours-andmitigating-the-harm-from-misinformation-and-disinformation

Organización Mundial de la Salud. (2020b, 07 16). Primera Conferencia de la OMS sobre Infodemiología. Organización Mundial de la Salud. Centro de prensa. https://www.who.int/es/ news-room/events/detail/2020/06/30/default-calendar/1st-who-infodemiology-conference

Organización Panamericana de la Salud. (2020). COVID-19: Orientaciones para comunicar sobre la enfermedad por el coronavirus 2019. Washington.

Raigada, J. L. P. (2002). Epistemología, metodología y técnicas del análisis de contenido. Sociolinguistic studies, 3(1), 1-42.

Ricard, J. \& Medeiros, J. (2020). Using misinformation as a political weapon: COVID-19 and Bolsonaro in Brazil. Harvard Kennedy School Misinformation Review, 1(3).

Riorda, M. (2011). Gestionando certidumbres: la comunicación de crisis no es comunicación gubernamental, electoral ni de riesgo. En Elizalde, L.; Fernández Pedemonte D. \& Riorda, M. La gestión del disenso: La comunicación gubernamental en problemas, La Crujía, 7-44.

Riorda, M. \& Conrero, S. (2017). La gestión de redes cambia toda la gestión: Los procesos de cambio organizacional en los gobiernos locales a partir del uso de las redes sociales digitales. Austral Comunicación, 6(1), 05-44. https://doi.org/10.26422/aucom.2017.0601.rio

Riorda, M. \& Valenti, P. (2016). Gobernautas y ciudadanos: los gobernantes latinoamericanos y la gestión de redes sociales. Banco Interamericano de Desarrollo (BID). 